\title{
A path to successful patient outcomes through aerosol drug delivery to children: a narrative review
}

\author{
Arzu Ari \\ Department of Respiratory Care, Texas State University, Round Rock, TX, USA \\ Correspondence to: Arzu Ari, PhD, RRT, PT, CPFT, FAARC, FCCP. Department of Respiratory Care, Texas State University, 200 Bobcat Way, \\ Willow Hall Suite \#214, Round Rock, TX, USA. Email: arzuari@txstate.edu.
}

\begin{abstract}
Although using aerosolized medications is a mainstay of treatment in children with asthma and other respiratory diseases, there are many issues in terms of device and interface selection, delivery technique and dosing, as well as patient and parental education that have not changed for half a century. Also, due to many aerosol devices and interfaces available on the market and the broad range of patient characteristics and requirements, providing effective aerosol therapy to children becomes a challenge. While aerosol delivery devices are equally effective, if they are age-appropriate and used correctly, the majority of aerosol devices require multiple steps to be used efficiently. Unfortunately, many children with pulmonary diseases have problems with the correct delivery technique and do not gain therapeutic benefits from therapy that result in poor disease management and increased healthcare costs. Therefore, the purpose of this paper is to review the current knowledge on aerosol delivery devices used in children and guide clinicians on the optimum device- and interface-selection, delivery technique, and dosing in this patient population. Strategies on how to deliver aerosolized medications in crying and distressed children and how to educate parents on aerosol therapy and promote patient adherence to prescribed medications are also provided. Future directions of aerosol therapy in children should focus on these issues and implement policies and clinical practices that highlight the potential solutions to these problems.
\end{abstract}

Keywords: Aerosols; nebulizers; inhalers; facemask; high flow nasal cannula; and children.

Submitted Feb 18, 2020. Accepted for publication Jul 03, 2020.

doi: $10.21037 / \mathrm{atm}-20-1682$

View this article at: http://dx.doi.org/10.21037/atm-20-1682

\section{Introduction}

Using the inhalation route for drug delivery is preferred in the treatment of children due to the direct delivery of the medication to the lung, rapid onset of action, and less systemic side effects compared to the other routes of administration (1). In addition, the direct delivery of medication to the lung minimizes the drug dosage needed for treatment efficacy (2).

Due to many aerosol devices and interfaces available on the market and the broad range of patient characteristics and requirements, providing effective aerosol therapy to children becomes a challenge. Therefore, the purpose of this paper is to review the current knowledge on aerosol delivery devices used in children and guide clinicians on the optimum device- and interface-selection, delivery technique, and dosing in this patient population. Strategies on how to deliver aerosolized medications in crying and distressed children and how to educate parents on aerosol therapy and promote patient adherence to prescribed medications are also provided. We present the following article in accordance with the Narrative Review reporting checklist (available at http://dx.doi.org/10.21037/atm-201682).

\section{Methods}

Using the keywords children, nebulizers, inhalers, facemask, high flow nasal cannula, and aerosols, the relevant published literature was searched in PubMed, Medline, CINAHL, 
and Science Direct until January 2020. While randomized clinical trials, in vitro/bench studies, prospective, and retrospective studies, survey research and review papers were included, abstracts, commentaries, and letters to the editors were excluded in this narrative review. Also, only articles published in English were included in this paper.

\section{Device selection}

Many aerosol delivery devices were developed more than 50 years ago. However, the special needs of children due to their airway anatomy, breathing pattern, physical and cognitive abilities have not been considered until recent years. Although the majority of current aerosol delivery devices were designed for adults, it is important to review their characteristics and technical features as they are also used in pediatrics and infants. Nebulizers, pressurized metered-dose inhalers, soft mist inhalers, and dry powder inhalers constitute the cornerstone of aerosol therapy in children. However, they differ from one another in terms of technical features, operations, breathing techniques, and ease of use that are explained below.

\section{Types of aerosol devices}

Nebulizers are widely used to deliver aerosolized medications to neonates, infants, and pediatrics. They transform liquid drugs into aerosols suspended in gas and one of the main advantages of nebulizers is that they can deliver a wide range of medications to children. However, they require power, have long treatment time compared to inhalers, and need extensive cleaning and maintenance after treatment. Also, contamination is a potential problem with nebulizers, and the power source needed to operate the nebulizer makes the therapy less portable and less convenient. Therefore, several modifications and innovations were made on the design of nebulizers over time to make them more efficient in the delivery of aerosolized medications to children. Some examples of those innovations include venturi devices, breathactuated, breath-synchronized, dosimetric, mesh, and smart nebulizers (3).

Jet nebulizers are the first-generation conventional nebulizers that are operated with compressed gas up to 10 $\mathrm{L} / \mathrm{min}$. Variations in the delivery efficiency of jet nebulizers were reported from brand to brand and unit to unit of the same brand (4-6). While they are labor-intensive and inefficient, they are also inexpensive compared to ultrasonic and mesh nebulizers. Ultrasonic nebulizers generate highfrequency vibrations in a piezoelectrical crystal to aerosolize the medication through sound waves. They are electrically powered and require gas flow generation through the fan, patient, or other gas sources to move aerosol from the device to the patient. The main problem with ultrasonic nebulizers is the heat generated during therapy that causes drug inactivation of proteins and an increase in drug concentration of suspension during therapy. Therefore, ultrasonic nebulizers are not used to deliver suspensions. Many clinicians consider mesh nebulizers as the nebulizer of choice because they are more efficient than other types of nebulizers available on the market (7-11). They create aerosols by pumping liquid through a mesh including thousands of apertures $(9,12)$. For the most part, these nebulizers are continuous, which limits inhaled dose.

Breath synchronized and smart nebulizers were developed to increase delivery efficiency and overcome issues with other types of nebulizers used in aerosol medicine. For example, adaptive aerosol delivery (AAD) technology and other variants determine the correct timing to deliver aerosolized medication and increase the precision and reproducibility of dosing through aerosol delivery at the beginning of inspiration (9,13-16). Smart nebulizers also improve lung deposition by reducing drug wastage during therapy and provide additional information regarding patient adherence to therapy and drug dosages delivered with each treatment (13-15,17-21).

Pressurized metered-dose inhalers (pMDIs) are a convenient therapeutic option for delivering aerosolized medications to children as they are portable and easy to operate. The treatment time with pMDIs is short, and they provide multi-dose convenience with consistent and accurate emitted dose (22-24). Issues of using the pMDI in children include difficulty in actuating the pMDI due to lack of hand strength, breath-hold, and inappropriate inspiratory flow (24-28).

Soft-mist inhalers (SMI) are small portable aerosol devices that are easy to operate, have short treatment time, and provides multi-dose convenience of liquid drug solution less than $20 \mu \mathrm{L}(29,30)$. They reduce oropharyngeal deposition through slowly moving aerosol clouds in a prolonged spray duration up to $1.5 \mathrm{~s}$. Thus, the SMI gives children enough time to coordinate their inhalation maneuver with the actuation of the SMI. Due to its small particle size and longer spray duration, the SMI decreases drug losses caused by inertial impaction and turbulent flow in the upper airway $(29,31)$. Therefore, 
lung deposition obtained with the SMI is relatively high compared to pMDI and DPI. Also, no volatile propulsive gases are required to operate SMI because it is mechanically pumped through a narrow nozzle system based on microchip technology (29-34). SMIs are not used in children less than 6 years of age.

Dry powdered inhalers (DPIs) deliver powdered medication in gelatin capsules, blisters, or reservoirs. Each capsule or blister includes a unit dose of powdered medication and carried via a substance like lactose. The unit-dose DPIs may be less convenient as each capsule needs to be loaded before treatment. Although the particles of DPIs are very large to deposit in the lungs, the turbulent airstream generated in the device during inspiration breaks up the particles to be carried into the lower airways. Therefore, the child's inspiratory flow rate is extremely important in creating the correct particle size of the medication within the respirable range during therapy. Each device requires different effort and inspiration flow rate to generate particles within the respirable range; however, it is known that fast forceful inhalations improve the efficiency of DPIs. Therefore, the child needs to achieve a certain inspiratory flow rate to receive a sufficient amount of aerosol particles to the lungs. Although younger children under the age of 6 years usually don't have the physical and cognitive abilities to generate adequate inspiratory flow for the effective use of DPIs, children who are 6 years of age and older may use DPIs independently. Since the successful delivery of aerosolized medication with DPIs relies on the magnitude of the inspiratory flow rate generated by the child, DPIs should not be used in acute conditions where the breathing of children is impaired.

\section{Device selection in children}

There are so many different aerosol delivery devices available on the market. Although they increase our chance to find the most appropriate delivery device for children, having so many options also make the device selection process complex for clinicians. Children possess different psychomotor skills in different age groups and there is no single aerosol device that meets the needs of all children due to heterogeneity of this patient population. Therefore, it is important to select an aerosol device based on the patient's age, cognitive and physical abilities. The ease of use, acceptability, and tolerance of the device by the child as well as parents' preference and perspectives should be considered when selecting an aerosol device for children with pulmonary diseases (35-39).

Figure 1 shows a screening tool for aerosol device selection in children. Either nebulizers or pMDIs with VHC should be used in infants less than 6 years of age as they don't have the physical and cognitive abilities to master specific inhalation techniques required by other aerosol devices such as DPIs $(35-37,40,41)$. Although nebulizers may be tolerated better in this patient population, they may be less desirable due to their long treatment time and less portability compared to pMDIs. Since pMDIs require a high degree of hand-breath coordination during therapy, it is important to use them with valued holding chambers (VHCs) in children less than 6 years old (41-43). Also, it is believed that hand-breath coordination and cognitive ability to control breathing develops by the age of 5 years. Therefore, it is essential to evaluate the child's physical and cognitive abilities before using SMI in children. DPIs are not used in this patient population due to the requirement for a fast-forceful inspiration with DPIs $(35-37,44,45)$.

Children between 6- and 12-year of age can generally perform specific inhalation techniques required by inhalers such as pMDIs, SMIs, or DPIs. Clinicians should train children and their parents on how to use DPIs correctly and effectively. Delivering aerosolized medications with nebulizers is also another alternative at this age.

Adolescents who are greater than 13 years of age can use all aerosol devices available on the market. The selection of an aerosol device in this patient population should be done based on their inspiratory flow rate, hand-breath coordination, preference, and willingness to use the device (Figure 1) $(36,37,40)$.

Also, the devices such as the In-CheckDial (Clement Clarke International Essex, United Kingdom) are valuable tools to assure that children can generate the minimum inspiratory flow rate with each DPI they are prescribed. Thus, the suitability of an inhaler for the child can be evaluated via an imprinted scale using different airway resistances and peak inspiratory flows through the InCheckDial (46-50). According to Amirav et al., the measurements of peak inspiratory flow with the In-Check Dial in 223 children with asthma with and without DPI experience showed that many children could not achieve the optimum inspiratory flow rate required with high resistance DPIs (48). As a handheld inspiratory air-flow meter, the In-Check Dial can simulate the resistance of an inhaler to identify the most appropriate inhaler for the child. Also, it is important to keep the aerosol device consistent to prevent any confusion with different inhalation techniques required 


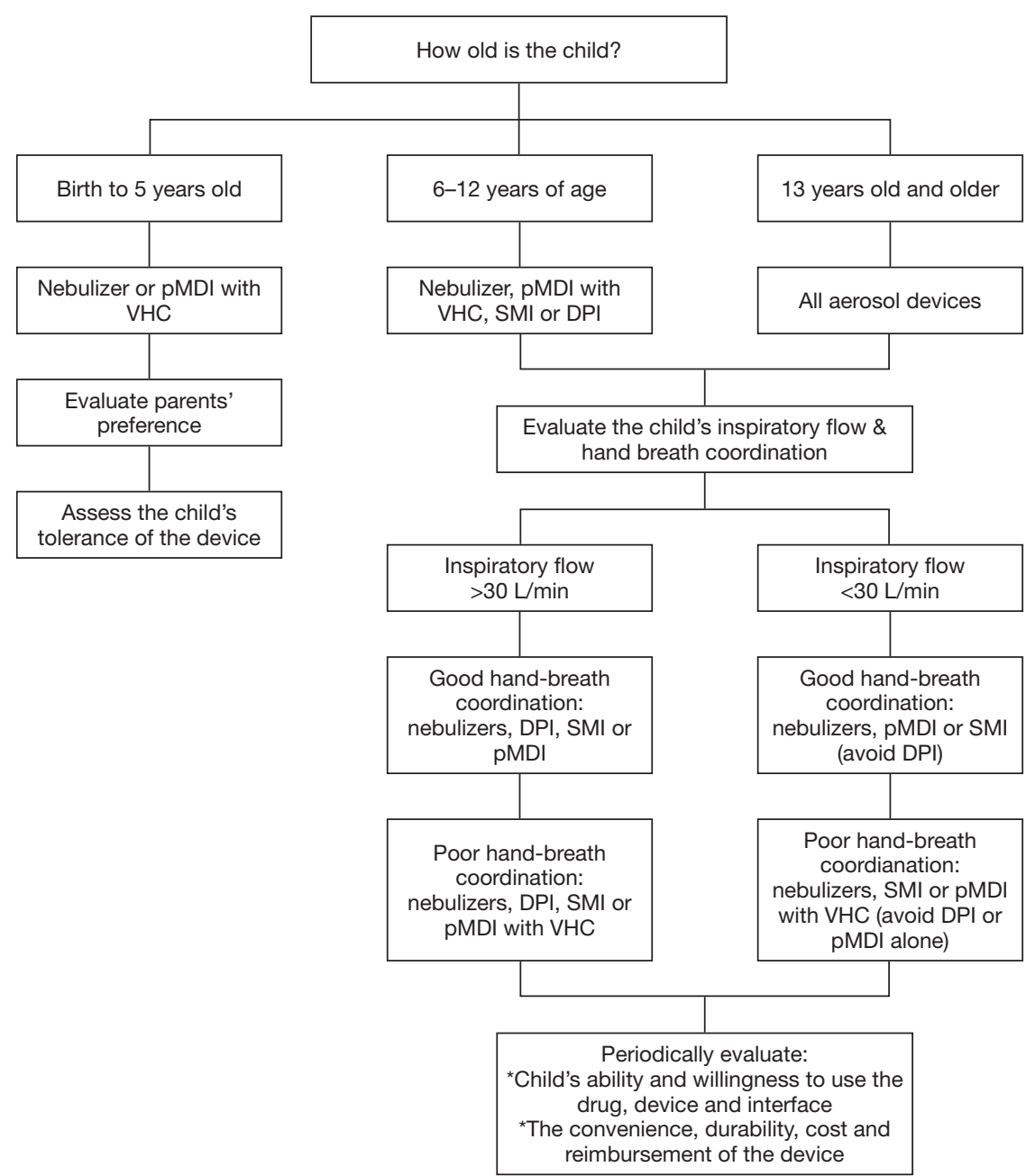

Figure 1 A screening tool for aerosol device selection in children based on child's age, hand-breath coordination, and inspiratory flow.

Table 1 Factors need to be considered in the selection of an aerosol device for children

\begin{tabular}{|c|c|}
\hline Factors & Considerations \\
\hline \multirow{2}{*}{$\begin{array}{l}\text { Drug-related } \\
\text { factors }\end{array}$} & Therapeutic aim of the drug \\
\hline & Availability of the drug in a specific device \\
\hline \multirow{4}{*}{$\begin{array}{l}\text { Device-related } \\
\text { factors }\end{array}$} & Delivery efficiency of the device \\
\hline & Cost and reimbursement of the device \\
\hline & Durability of the device \\
\hline & Cleaning and maintenance of the device \\
\hline \multirow{3}{*}{$\begin{array}{l}\text { Patient-related } \\
\text { factors }\end{array}$} & Age \\
\hline & Physical and cognitive abilities \\
\hline & $\begin{array}{l}\text { Patient's tolerance, acceptance, and } \\
\text { preference of the device }\end{array}$ \\
\hline
\end{tabular}

with various inhalers. After selecting an appropriate aerosol device based on the child's age and psychomotor skills, the same type of device should be used for the delivery of different inhaled drugs (36,51-53). Table 1 lists factors that need to be considered in the selection of an aerosol device for children.

\section{Interface selection}

\section{Types of delivery interface}

The different types of interfaces such as mouthpiece, facemask, nasal cannula, pacifier mask, spacers, and VHCs are used for aerosol drug delivery to children $(54,55)$. 


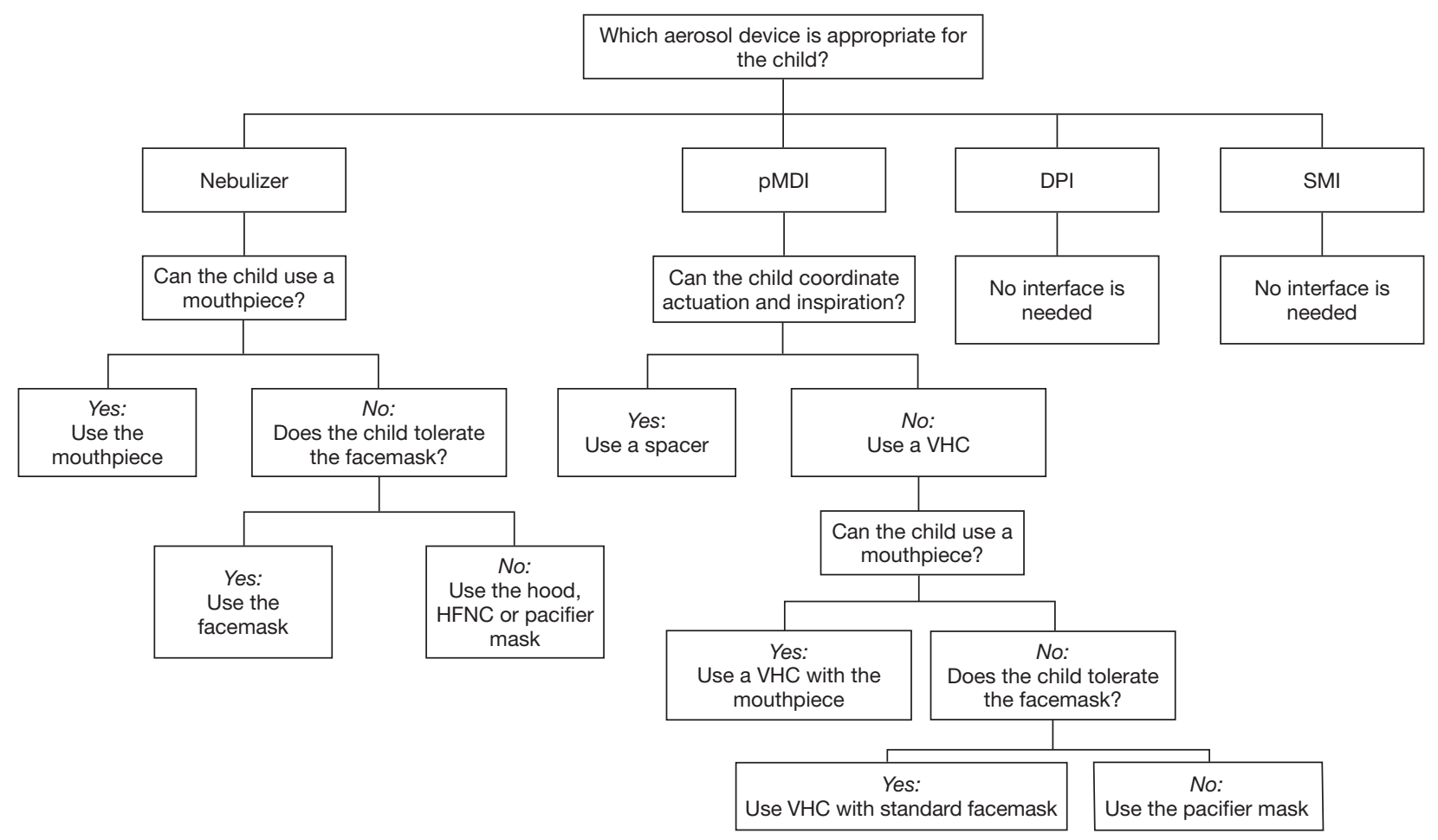

Figure 2 Recommendations concerning interface selection based on the type of aerosol device.

\section{Interface selection in children}

There is no single interface that meets the needs of all children with pulmonary diseases due to patient heterogeneity and their variation in psychomotor skills. The need for and type of delivery interface will depend upon the patient's age, tolerance, and acceptance of the interface during treatment. The precise age at which interface is required depends on the physical and cognitive abilities of each child. Also, interfaces that are easily tolerated by children should be used for aerosol therapy. Figures 2,3 provide further recommendations with respect to interface selection based on the type of aerosol device and the age of the patient, respectively.

The mouthpiece is commonly used in older children and may deliver up to twice as much aerosol drug delivery compared to a facemask $(8,10,54,56)$. Although the mouthpiece is the preferred interface for aerosol delivery, children less than 3 years old may not reliably maintain a seal around the mouthpiece during treatment. Therefore, other interfaces such as a facemask, pacifier mask, nasal mask, hood, or nasal cannula are useful in this patient population.
Facemasks vary in terms of weight, flexibility, dead space, and design. A lightweight, flexible facemask with anatomical contours that has small dead space should be preferred in children to increase inhaled dose and tolerability during aerosol therapy (57-60). The design of facemasks is divided into two categories: (I) front-loaded facemasks and (II) bottom-loaded facemasks. While front-loaded facemasks direct aerosolized medication to the oronasal area, bottomloaded facemasks lead the particles to the upper part of the mask. The front-loaded facemask tends to be more efficient than bottom-loaded face masks and results in a less aerosol deposition to the eyes and face of children (61-66). Aerosol masks should be securely attached to the face. Even small leaks can greatly reduce inhaled dose. Up to $49 \%$ of children do not tolerate face masks, with fussing and crying which greatly reduces lung dose.

The pacifier mask (Soother Mask, InspiRx, Somerset, New Jersey) is a relatively new children-oriented mask designed to improve lung deposition by eliminating fear, discomfort, and crying in infants and toddlers during aerosol therapy (Figure 4). The child's pacifier is attached to the mask to improve tolerance to the treatment and achieve a good facemask seal when delivering aerosolized 


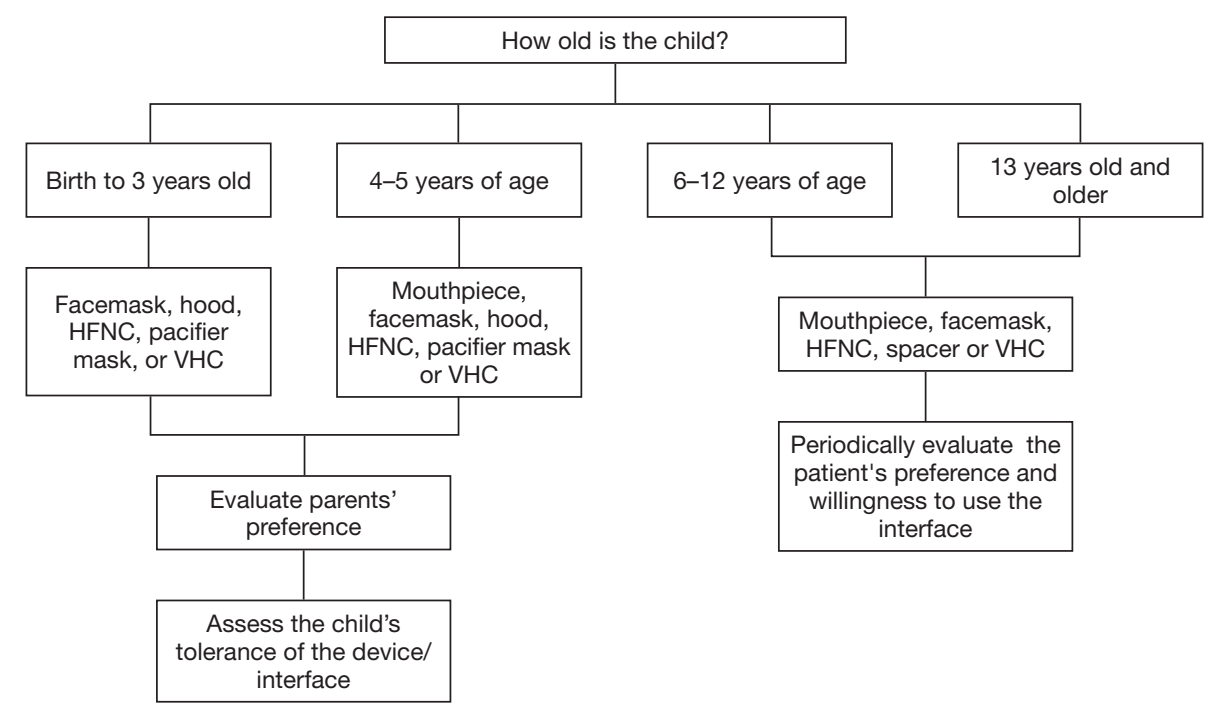

Figure 3 Recommendations for interface selection based on the age of the patient.

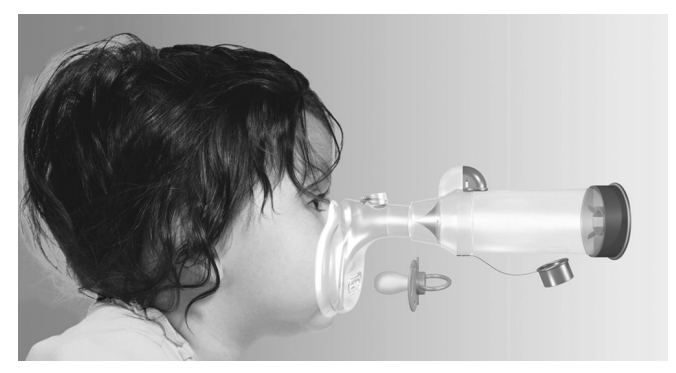

Figure 4 Soother mask (reproduced with permission from InspiRx, Somerset, New Jersey).

medications. Sucking the pacifier during therapy helps achieve the optimum face-mask seal during therapy. Although the comparisons of the pacifier mask with standard face mask showed similar lung deposition in infants less than 1-year-old (67), using a pacifier during aerosol therapy may calm the child and improve compliance to prolonged treatment time in young children (67-69).

Transnasal pulmonary aerosol delivery allows administration of oxygen and aerosol through the same nasal cannula and has become popular recently because young children are primarily nose breathers and tend to tolerate nasal prongs better than aerosol face masks. Studies reported that the efficiency of nasal aerosol delivery is superior to the oral delivery of aerosols in this patient population $(70,71)$. The nasal cannula has been used in studies in which a mesh nebulizer was placed on the inspiratory inlet of a heated humidifier in simulated pediatrics, infants and premature babies and reports that aerosolized medications can be delivered through nasal cannula effectively $(8,72-78)$. While decreasing flow rate improves lung deposition in children, a recent in vitro study showed that transnasal aerosol delivery is greater at $0.25 \mathrm{~L} / \mathrm{kg} / \mathrm{min}$ than lower flows (76). Nebulizer placement prior to the humidifier allows larger particles to deposit in the humidifier chamber, reducing rainout at the cannula while increasing inhaled aerosol deposition compared to nebulizer placement proximal to the patient $(73,79-81)$. During nasal oxygen administration, attempts to place aerosol facemasks over the cannula reduces inhaled dose. Greater aerosol delivery efficiency is achieved when the nasal cannula is removed (78). However, it is essential to weigh the benefits of increased aerosol deposition against the risks with interrupted oxygen delivery and lung derecruitment when the nasal cannula is removed for aerosol drug delivery to children.

Although several types of nasal masks were designed in recent years to increase the inhaled dose in children, an in vitro study showed that aerosol deposition obtained with the nasal mask was less than that with the facemask in simulated infants and children using a jet nebulizer (66).

In children who cannot use the mouthpiece or tolerate a facemask, using a hood for aerosol drug delivery may offer a good alternative, if it does not agitate the infant or make them cry during therapy (82-86). The delivery efficiency of the hood $(2.6 \%)$ is similar to the facemask $(2.4 \%)$ in children with wheezing (85), while patient discomfort and 
treatment time with the hood is less than the facemask (84). Although aerosol deposition in the eye is a concern with the use of hood, previous research showed less facialocular deposition in the face-side position than the faceup position (87). Parents also preferred using the hood compared to the facemask (86).

Spacers and VHCs are the delivery interfaces used with pMDIs. While both them reduce oropharyngeal deposition, it is important to note that only VHCs decrease the need for hand-breath coordination during therapy. Spacers do not have one-way valves as opposed to VHCs that include low-resistance one-way valves preventing aerosols exiting the VHC until inspiration starts. Clinicians should prefer VHCs especially when the child has distressed breathing. Also, small volume VHC should be selected in infants and toddlers so that aerosol concentration in the add-on device will be higher and the child can inhale all medication from it with a few inspirations $(35-37,58,60)$. Also, VHCs should be used with a facemask instead of a mouthpiece in small children because they don't have the physical ability to seal the mouthpiece during therapy. While the large volume of spacers/VHCs can be an issue in infants and toddlers, no significant difference between small- and large-volume spacers was found on the bronchodilator response of older children with asthma (88).

\section{Dosing}

Children have smaller airways, lower tidal volume, lower vital capacity, and functional residual capacity than adults; therefore, most of the medication deposits in the oropharyngeal region and lung deposition in children is less than adults. Although children have smaller airways, decreased lung doses are appropriate for them due to their smaller lung surface area and body mass. As a result, the weight-corrected lung doses in children are similar to adults $(35,36,40,89)$. Aerosols deposit in the central airways and poorly distributed in the lung due to non-uniform diseases such as localized bronchiectasis. Also, conditions such as purulent secretions in the airways, laryngospasm, enlarged tonsils and adenoids limit the delivery of aerosolized medications to the lung peripheries (45).

The particle size is an important concept in dosing and the efficacy of aerosol therapy. While particles greater than $5 \mu \mathrm{m}$ impact in the oropharyngeal area, aerosol particles less than $1 \mu \mathrm{m}$ may remain in suspension and are exhaled during therapy. Therefore, particles with a mass median aerodynamic diameter (MMAD) between 1 and $5 \mu \mathrm{m}$ are considered optimum in adults. However, optimal particle size for effective delivery of aerosolized medications to children is not known.

Also, most of the aerosolized medications have not been approved for use in pediatrics less than 2 years old. While label doses may be weight appropriate in older children, research on what dose is appropriate for small children is still lacking. Therefore, the lowest dose that works for this patient population can be considered as the correct dose to use during aerosol therapy.

\section{Delivery technique}

Aerosol delivery devices are equally effective if they are ageappropriate and used correctly $(36,37,52,90)$. However, the majority of aerosol devices require multiple steps to be used efficiently and many children with pulmonary diseases have problems with the correct delivery technique (91-94) and do not gain therapeutic benefits from therapy that result in poor disease management and increased healthcare costs $(95,96)$. Multiple factors such as the device characteristics, children's psychomotor skills, and the healthcare professionals' knowledge lead to errors with the use of inhalers in children. For instance, current aerosol devices are designed for aerosol delivery to adults and each aerosol device requires a certain level of physical and cognitive ability, as well as hand strength, coordination, dexterity, and lung capacity to ensure optimal inhaler use. Also, health care professionals play a critical role in teaching children the correct technique and in maintaining their correct use of the device over time (97). Previous research showed that only $15 \%$ to $69 \%$ of clinicians across all disciplines could use aerosol devices correctly $(25,98-101)$. This leads to an incorrect selection of aerosol devices and a lack of patient education and training on delivery techniques. Although children's inhalation technique is poor, previous research documented that patient education, repeated follow-ups and monitoring is effective in improving their inhalation techniques (102-105). Therefore, clinicians should be aware of the issues with the delivery technique of each device, teach children how to use their aerosol devices correctly, and monitor their technique at every opportunity. Since a correct inhalation technique erodes over time, clinicians should also provide instructions repeatedly to children/ parents and follow up with them even though it is timeconsuming. The following section explains issues with the delivery technique of each device and provides potential solutions to these problems. 


\section{Delivery technique with pMDIs}

While the pMDIs appear to be easy to use initially, using them effectively can be a challenge for children due to the requirements of shaking, priming, hand-breath coordination, and breath-hold (103,106-108). The pMDIs should be shaken and primed before therapy to ensure a homogenous mixture of the content and proper filling of the metering chamber. Otherwise, the drug is separated from the other ingredients in the canister of the pMDI when it is new and has not been used for 24 hours up to 7 days, depending on the drug formulation. After the patient releases a metered volume of drug, and propellants by pressing down the canister to actuate a dose of medication, taking a deep, slow breath may be complex for this patient population. Also, children may not achieve a good handbreath coordination and breath-holding required for the effective use of pMDIs. They may not have the strength and dexterity of their fingers to actuate the pMDI during therapy when they need to use the pMDI independently. Sometimes, they inhale either too early or too late after the actuation of the pMDI $(95,108,109)$. A clinical study conducted on children in the primary care setting showed that only $8 \%$ of children were able to demonstrate the correct delivery technique with pMDIs (110).

Due to issues of using pMDI alone in children, add-on devices such as spacers and VHCs are used with pMDIs to optimize aerosol drug delivery by providing slow velocity and small particle size during therapy. Using a pMDI with a VHC will overcome the hand-breath coordination problem in children and improve lung deposition. Due to the distance between the pMDI and the VHC, larger particles deposit on the sides of the chamber and help smaller particles deliver to the lungs. It will reduce the oropharyngeal deposition that will lead to fewer side effects in the upper airways such as thrush when corticosteroids are used in the treatment of children with pulmonary diseases.

While there are many different types of pMDI add-on devices are available on the market, they differ in terms of size, shape, and material used in the device. The spacers and VHCs have various sizes ranging from 50 to $750 \mathrm{~mL}$. Since children have low tidal volumes, low volume spacers/VHCs are recommended for aerosol drug delivery to this patient population. Otherwise, when a large volume spacer is used with pMDI, the child will need to take several breaths to empty the spacer and increase the delivery of aerosolized medications to the lungs. According to the study conducted by Schultz et al., two tidal breaths are sufficient enough to receive aerosol from a small volume spacer while three breaths should be taken with larger spacers for optimum drug delivery to children between 2- and 7-year of age (111).

The breathing technique with add-on devices is simple and only requires normal tidal breathing in small children less than 4 years of age who need a facemask attached to the spacer/VHC as they cannot hold the mouthpiece tightly with their lips during therapy. In small children, parents should deliver aerosolized medications with VHCs and ensure that the valve functions properly. Previous research showed a significant improvement with a deep inspiration followed by breath-hold using the pMDI and VHC in children from 4- to 15 -year-old (112). Also, it is important to note that multiple actuations into the spacer/ VHC will decrease aerosol drug delivery to the child, and the reduction in lung dose will be more with small low volume spacers $(28,113)$. Another issue with spacers/VHCs is its electrostatic charge that will reduce the inhaled dose. Therefore, washing spacers with detergent is recommended before use to eliminate static charge and increase aerosol delivery to children $(89,114-117)$. Clinicians can also use non-electrostatic spacers for the treatment of children, when available (118).

\section{Delivery technique with DPIs}

Unlike pMDIs, DPIs are breath-actuated. Therefore, they don't require hand-breath coordination during therapy. Children should be trained not to exhale into the inhaler after the dose is loaded because it will increase the humidity in the device and blow out the dose. Also, DPIs should not be stored in high humidity conditions that will dissolve the drug or form large agglomerates, which will be difficult to disperse into small particles during therapy.

Regardless of the type of inhaler used in the treatment of children with pulmonary diseases, small children exhale most of the medication because they cannot hold their breath after inspiration from the inhaler. However, it is important to note that breath-holding of 5 seconds is recommended with pMDIs in children up to 10 years of age to improve peripheral deposition of the medication (112).

\section{Delivery technique with nebulizers}

The delivery technique with nebulizers only requires normal tidal breathing, and a breath-hold is not needed for effective aerosol delivery, unlike inhalers. 


\section{Delivery technique with different interfaces}

In children older than 3 years of age, a mouthpiece should be sealed with lips, and children should be instructed to take breaths through the mouth to increase the efficiency of the treatment. When a facemask is used for the delivery of aerosolized medications to children, it is essential to have a tight face-mask seal during therapy. While a good facemask seal will increase the inhaled dose and reduce aerosol deposition in the eye and face of children, it also leads to crying, fussing and intolerance of the mask by children (62-64,119-122). In this case, another interface such as the hood, nasal cannula, or pacifier mask should be used for aerosol therapy. Also, drug deposition in the eye of children is an issue especially with inhaled anticholinergic drugs that may cause blurring vision, pupil dilatation, and glaucoma. Therefore, clinicians should monitor children with caution during aerosol therapy with the facemask and hood.

Although the blow-by technique was used in crying and uncooperative children by directing aerosol from the nebulizer to the child's face, it is well known that the blow-by technique is inefficient in delivering aerosolized medications to this patient population $(65,123,124)$. Therefore, clinicians should not use the blow-by technique during aerosol therapy.

\section{Crying and distressed children}

Crying decreases inhaled dose due to a very long expiration followed by short and fast inspiration. Gastrointestinal deposition of aerosols was $50 \%$ higher in crying children than their non-crying peers (125), and it is a challenge to have a good face-mask seal during aerosol therapy in distressed and crying children. Therefore, previous research reported that lung deposition in crying babies was $0.35 \%$ as opposed to $2 \%$ with pMDIs in quite breathing (126) Since the delivery of aerosols with nebulizers was also 4-fold less in crying infants (127), it is essential to decrease distress and comfort babies through games or another effective way of distraction before aerosol therapy. Alternatively, previous research suggested administering aerosolized medications to children while they are asleep (128). Since the breathing pattern of children is more regular during sleep than when they are awake, the delivery of aerosolized medications during sleep may improve lung deposition and patient outcomes. However, it is essential not to wake children with the administration of aerosolized medications because previous research showed that $69 \%$ of the children woke up and $75 \%$ of them distressed during treatment (129).

\section{Parental education}

Parental education is important in the treatment of children. However, aerosolized medications are usually prescribed without any information or demonstration on how to use the aerosol device and interface effectively. Therefore, parents do not know what to do in difficult situations such as crying and fussing during aerosol therapy with the facemask. They may either force their children to keep the mask on or end up using the blowby technique, which will reduce the efficiency of aerosol therapy significantly. As a result, parents report poor clinical response to the prescribed medications. In this case, clinicians usually change the type of medication prescribed or increase the dose by assuming the parents used the correct delivery technique during aerosol therapy. Then, parents are concerned about the side effects of the medications prescribed to their children. Therefore, it is important to explain what is prescribed for the treatment of their children, why it is important to take the medication, and how it is going to help their children. The side effects of the medications should be discussed and the barriers to adhere to the treatment should be explored. Also, using a shared vision about the disease and its treatments will lead to success in disease management $(130,131)$.

Although parents understand the importance of using aerosol devices correctly, they will not be able to use them without effective instructions. Therefore, it is important to prepare one-on-one individualized education sessions and provide effective instructions to parents that will improve treatment adherence and clinical outcomes (132). While written instructions and videos are helpful; each training session should include verbal instructions on how to use aerosol devices correctly that accompanied by repeated demonstrations and follow-ups. Since the correct inhalation techniques erode over time, instructions on how to use the device correctly should be given repeatedly to achieve and maintain the correct inhalation technique in children. Verbal instruction, combined with demonstrations and repetitive training over time will help maintain the correct delivery technique during aerosol therapy. Clinicians can use simple teaching devices to develop the psychomotor skills of parents needed to use an aerosol device effectively. They can also prepare a personalized inhaler technique labels that highlight the incorrect steps on the label that will help them when they deliver inhaled medications to their 
Table 2 General principles recommended for parental education

Prepare for one-on-one individualized training sessions

Provide effective instructions

Use training tools to teach how to use inhalers effectively

Check the patient's inhalation technique

Correct the errors in breathing techniques

Prepare personalized inhaler technique labels

Promote adherence to therapy

Follow-up with parents

children at home (133).

It is also essential to promote adherence to therapy in children through their parents. Several strategies that can be used by clinicians to improve treatment adherence include: (I) educate parents about the role, effectiveness and side effects of inhaled medications prescribed for the patient, (II) educate parents about severity of disease and risk of not using the medication, (III) determine whether the cost of medication is an issue and search for lower-cost alternatives, (IV) simplify aerosol-dosing regimen as much as possible by using the combination of aerosol formulations (bronchodilator plus corticosteroids) or reducing treatment frequency to daily or twice daily medications, and (V) provide a written treatment plan specifying actions and times that will help parents know what to do in critical situations. Since it is imperative to include parental education in future practices with the delivery of aerosolized medications to children, Table 2 provides general principles recommended for parental education.

Also, it is important to note that device and interface selection as well as treatments and dosing are different in acute care settings designed to treat an acute condition that requires immediate evaluation and treatment with continuous monitoring of the patient. For instance, nebulizers may be used for aerosol drug delivery to children instead of inhalers in acute care. Usually, children in respiratory distress do not tolerate conventional interfaces such as facemask, and clinicians choose to deliver aerosolized medications via HFNC to improve patient comfort and tolerance during aerosol therapy. The drug dosages used in acute care is usually greater than the dosages used in stable patients. Since a patient-centered approach is used in acute care settings, clinicians also focus on parental education and guidance to help them support their child's progress after discharge. Interacting with patients and their parents at the hospital will help clinicians teach the necessary information about what type of treatment they need to do at home, why it is important to adhere to prescribed therapy and how they should use their aerosol delivery devices when they are discharged. Thus, patients and their parents can have the necessary knowledge and skills needed for effective aerosol therapy in children before they return home.

\section{Limitations and future research}

Aerosol drug delivery to children has been improved if we had a better understanding of the efficiency and functional differences of aerosol devices, interfaces, drug formulations, and dosages used in premature babies, toddlers, and children. Since the medication and dosage recommendations depend on the delivery technique, aerosol device, and interface used during therapy, it is important to prepare guidelines that specify these parameters to help clinicians select appropriate delivery systems for children of various ages. While the majority of the studies on aerosol drug delivery to this patient population are in vitro/bench studies, it is essential to standardize in vitro studies with better lung models that replicate children's anatomy and breathing parameters. Therefore, clinical research that will evaluate the safety, therapeutic efficacy, and delivery efficiency of aerosol therapy is needed.

In summary, although using aerosolized medications is the mainstay of treatment in children, there are many issues faced by clinicians in terms of device and interface selection, delivery technique and dosing, as well as patient and parental education that have not changed for half a century. Future directions of aerosol therapy in children should focus on these issues and implement policies and clinical practices that highlight the potential solutions to these problems.

\section{Acknowledgments}

I would like to thank Dr. Jim Fink for his invitation to write this paper.

Funding: None.

\section{Footnote}

Provenance and Peer Review: This article was commissioned by the Guest Editors (Dr. James B. Fink and Dr. Zhe Luo) for the series "Medical Aerosol in Acute and Critical Care" published in Annals of Translational Medicine. The article 
was sent for external peer review organized by the Guest Editors and the editorial office.

Reporting Checklist: The author has completed the narrative review reporting checklist. Available at http://dx.doi. org/10.21037/atm-20-1682

Conflicts of Interest: The author has completed the ICMJE uniform disclosure form (available at http://dx.doi. org/10.21037/atm-20-1682). The series "Medical Aerosol in Acute and Critical Care" was commissioned by the editorial office without any funding or sponsorship. AA reports personal fees from Bayer Pharmaceuticals, personal fees from Sunovion Pharmaceuticals, grants and personal fees from Aerogen Ltd., Grants from ARC Medical, outside the submitted work. The author has no other conflicts of interest to declare.

Ethical Statement: The author is accountable for all aspects of the work in ensuring that questions related to the accuracy or integrity of any part of the work are appropriately investigated and resolved.

Open Access Statement: This is an Open Access article distributed in accordance with the Creative Commons Attribution-NonCommercial-NoDerivs 4.0 International License (CC BY-NC-ND 4.0), which permits the noncommercial replication and distribution of the article with the strict proviso that no changes or edits are made and the original work is properly cited (including links to both the formal publication through the relevant DOI and the license). See: https://creativecommons.org/licenses/by-nc-nd/4.0/.

\section{References}

1. van Aalderen WM, Garcia-Marcos L, Gappa M, et al. How to match the optimal currently available inhaler device to an individual child with asthma or recurrent wheeze. NPJ Prim Care Respir Med 2015;25:14088.

2. Goralski JL, Davis SD. Breathing easier: addressing the challenges of aerosolizing medications to infants and preschoolers. Respir Med 2014;108:1069-74.

3. Ari A, Fink JB. Recent advances in aerosol devices for the delivery of inhaled medications. Expert Opin Drug Deliv 2020;17:133-44.

4. Yilmaz O, Sogut A, Kose U, et al. Influence of ambulatory inhaled treatment with different devices on the duration of acute asthma findings in children. J
Asthma 2009;46:191-3.

5. Alvine GF, Rodgers P, Fitzsimmons KM, et al. Disposable jet nebulizers. How reliable are they? Chest 1992;101:316-9.

6. Berg EB, Picard RJ. In-vitro delivery of budesonide from 30 jet nebulizer/compressor combinations using infant and child breathing patterns. Respir Care 2009;54:1671-8.

7. Pritchard JN, Hatley RH, Denyer J, et al. Mesh nebulizers have become the first choice for new nebulized pharmaceutical drug developments. Ther Deliv 2018;9:121-36.

8. Ari A. Effect of nebulizer type, delivery interface, and flow rate on aerosol drug delivery to spontaneously breathing pediatric and infant lung models. Pediatr Pulmonol 2019;54:1735-41.

9. Ari A. Jet, mesh and ultrasonic nebulizers: An evaluation of nebulizers for better clinical practice. Rev Mal Respir 2012;29:656-63.

10. Ari A, de Andrade AD, Sheard M, et al. Performance Comparisons of Jet and Mesh Nebulizers Using Different Interfaces in Simulated Spontaneously Breathing Adults and Children. J Aerosol Med Pulm Drug Deliv 2015;28:281-9.

11. Ari A, Atalay OT, Harwood R, et al. Influence of nebulizer type, position, and bias flow on aerosol drug delivery in simulated pediatric and adult lung models during mechanical ventilation. Respir Care 2010;5 5:845-51.

12. Dhand R. Nebulizers that use a vibrating mesh or plate with multiple apertures to generate aerosol. Respir Care 2002;47:1406-16; discussion 16-8.

13. Nikander K. Adaptive aerosol delivery: the principles. Eur Respir Rev 1997;7:385-7.

14. Denyer J. Adaptive aerosol delivery in practise. Eur Respir Rev 1997;7:388-9.

15. Denyer J, Nikander K, Smith N. Adaptive aerosol delivery (AAD) technology. Expert Opin Drug Deliv 2004;1:165.

16. Smaldone GC. Smart nebulizers. Respir Care 2002;47:1434-41; discussion 41-4.

17. Denyer J, Prince I, Dixon E, et al. Evaluation of the Target Inhalation Mode (TIM) breathing maneuver in simulated nebulizer therapy in patients with cystic fibrosis. J Aerosol Med Pulm Drug Deliv 2010;23 Suppl 1:S29-36.

18. Denyer J, Black A, Nikander K, et al. Domiciliary experience of the Target Inhalation Mode (TIM) breathing maneuver in patients with cystic fibrosis. J Aerosol Med Pulm Drug Deliv 2010;23 Suppl 1:S45-54.

19. Denyer J. Adherence monitoring in drug delivery. Expert Opin Drug Deliv 2010;7:1127-31. 
20. Nikander K, Arheden L, Denyer J, et al. Parents' adherence with nebulizer treatment of their children when using an adaptive aerosol delivery (AAD) system. J Aerosol Med 2003;16:273-81.

21. Geller DE, Kesser KC. The I-neb Adaptive Aerosol Delivery System enhances delivery of alpha1-antitrypsin with controlled inhalation. J Aerosol Med Pulm Drug Deliv 2010;23 Suppl 1:S55-9.

22. Rubin BK, Fink JB. Optimizing aerosol delivery by pressurized metered-dose inhalers. Respir Care 2005;50:1191.

23. Rubin BK, Fink JB. Aerosol therapy for children. Respir Care Clin N Am 2001;7:175-213.

24. Rubin BK. Air and soul: the science and application of aerosol therapy. Respir Care 2010;55:911-21.

25. Fink JB, Rubin BK. Problems with inhaler use: a call for improved clinician and patient education. Respir Care 2005;50:1360-74.

26. Rau JL. The inhalation of drugs: advantages and problems. Respir Care 2005;50:367-82.

27. McFadden ER, Jr. Improper patient techniques with metered dose inhalers: clinical consequences and solutions to misuse. J Allergy Clin Immunol 1995;96:278-83.

28. Mitchell JP, Nagel MW. Valved holding chambers (VHCs) for use with pressurised metered-dose inhalers (pMDIs): a review of causes of inconsistent medication delivery. Prim Care Respir J 2007;16:207-14.

29. Dalby R, Spallek M, Voshaar T. A review of the development of Respimat Soft Mist Inhaler. Int J Pharm 2004;283:1-9.

30. Perriello EA, Sobieraj DM. The Respimat Soft Mist Inhaler, a Novel Inhaled Drug Delivery Device. Conn Med 2016;80:359-64.

31. Newman SP, Brown J, Steed KP, et al. Lung deposition of fenoterol and flunisolide delivered using a novel device for inhaled medicines: comparison of RESPIMAT with conventional metered-dose inhalers with and without spacer devices. Chest 1998;113:957-63.

32. Anderson P. Use of Respimat Soft Mist inhaler in COPD patients. Int J Chron Obstruct Pulmon Dis 2006;1:251-9.

33. Hochrainer D, Holz H, Kreher C, et al. Comparison of the aerosol velocity and spray duration of Respimat Soft Mist inhaler and pressurized metered dose inhalers. J Aerosol Med 2005;18:273-82.

34. Pitcairn G, Reader S, Pavia D, et al. Deposition of corticosteroid aerosol in the human lung by Respimat Soft Mist inhaler compared to deposition by metered dose inhaler or by Turbuhaler dry powder inhaler. J Aerosol
Med 2005;18:264-72.

35. Ari A, Fink JB. Aerosol therapy in children: challenges and solutions. Expert Rev Respir Med 2013;7:665-72.

36. Ari A, Fink J. Guidelines to aerosol devices in infants, children and adults: which to choose, why and how to achieve effective aerosol therapy? Expert Rev Respir Med 2011;5:561-72.

37. Ari A, Restrepo RD. Aerosol delivery device selection for spontaneously breathing patients: 2012. Respir Care 2012;57:613-26.

38. Ari A, Fink JB. Effective bronchodilator resuscitation of children in the emergency room: device or interface? Respir Care 2011;56:882-5.

39. Ari A, Fink JB. Aerosol Delivery Devices for the Treatment of Adult Patients in Acute and Critical Care. Curr Pharm Biotechnol 2016;17:1268-77.

40. Ari A. Optimal delivery of aerosol drugs in the pediatric/ neonatal patient populations. AARC Times 2009;33:24-6.

41. Everard ML. Aerosol delivery to children. Pediatr Ann 2006;35:630-6.

42. Everard ML. Inhalation therapy for infants. Adv Drug Deliv Rev 2003;55:869-78.

43. Everard ML. Inhaler devices in infants and children: challenges and solutions. J Aerosol Med 2004;17:186-95.

44. Everard ML. Guidelines for devices and choices. J Aerosol Med 2001;14 Suppl 1:S59-64.

45. Trend S, von Ungern-Sternberg BS, Devadason SG, et al. Current options in aerosolised drug therapy for children receiving respiratory support. Anaesthesia 2017;72:1388-97.

46. van der Palen J. Peak inspiratory flow through diskus and turbuhaler, measured by means of a peak inspiratory flow meter (In-Check DIAL). Respir Med 2003;97:285-9.

47. Azouz W, Chrystyn H. Clarifying the dilemmas about inhalation techniques for dry powder inhalers: integrating science with clinical practice. Prim Care Respir J 2012;21:208-13.

48. Amirav I, Newhouse MT, Mansour Y. Measurement of peak inspiratory flow with in-check dial device to simulate low-resistance (Diskus) and high-resistance (Turbohaler) dry powder inhalers in children with asthma. Pediatr Pulmonol 2005;39:447-51.

49. Chrystyn H. Is inhalation rate important for a dry powder inhaler? Using the In-Check Dial to identify these rates. Respir Med 2003;97:181-7.

50. Fiato KL, Iwamoto GK, Harkins MS, et al. Monitoring flow rates and retention of inhalation techniques using the in-check dial device in adult asthmatics. J Asthma 2007;44:209-12. 
51. van Der Palen J, Klein KC, van Herwaarden CL, et al. Multiple inhalers confuse asthma patients. Eur Respir J 1999;14:1034-7.

52. Dolovich MB, Ahrens RC, Hess DR, et al. Device selection and outcomes of aerosol therapy: evidencebased guidelines: American College of Chest Physicians/ American College of Asthma, Allergy, and Immunology. Chest 2005;127:335-71.

53. Ari A. Patient education and adherence in aerosol therapy. Respir Care 2015;60:941-55; discussion 955-7.

54. Ari A. Drug delivery interfaces: A way to optimize inhalation therapy in spontaneously breathing children. World J Clin Pediatr 2016;5:281-7.

55. Ari A. Aerosol Drug Delivery Through High Flow Nasal Cannula. Curr Pharm Biotechnol 2017;18:877-82.

56. Ditcham W, Murdzoska J, Zhang G, et al. Lung deposition of $99 \mathrm{~m}$ Tc-radiolabeled albuterol delivered through a pressurized metered dose inhaler and spacer with facemask or mouthpiece in children with asthma. J Aerosol Med Pulm Drug Deliv 2014;27:S63-75.

57. Amirav I, Mandelberg A. Face masks for aerosols-there is more science. Pediatr Pulmonol 2010;45:221-3.

58. Amirav I, Newhouse MT. Dead space variability of face masks for valved holding chambers. Isr Med Assoc J 2008;10:224-6.

59. Amirav I, Newhouse MT. Aerosol therapy in infants and toddlers: past, present and future. Expert Rev Respir Med 2008;2:597-605.

60. Amirav I, Newhouse MT. Review of optimal characteristics of face-masks for valved-holding chambers (VHCs). Pediatr Pulmonol 2008;43:268-74.

61. Sangwan S, Gurses BK, Smaldone GC. Facemasks and facial deposition of aerosols. Pediatr Pulmonol 2004;37:447-52.

62. Smaldone GC. Assessing new technologies: patient-device interactions and deposition. Respir Care 2005;50:1151-60.

63. Smaldone GC, Berg E, Nikander K. Variation in pediatric aerosol delivery: importance of facemask. J Aerosol Med 2005;18:354-63.

64. Smaldone GC, Sangwan S, Shah A. Facemask design, facial deposition, and delivered dose of nebulized aerosols. J Aerosol Med 2007;20 Suppl 1:S66-75; discussion S75-7.

65. Lin HL, Restrepo RD, Gardenhire DS, et al. Effect of face mask design on inhaled mass of nebulized albuterol, using a pediatric breathing model. Respiratory Care 2007;52:1021-6.

66. El Taoum KK, Xi J, Kim J, et al. In Vitro Evaluation of Aerosols Delivered via the Nasal Route. Respir Care
2015;60:1015-25.

67. Amirav I, Luder A, Chleechel A, et al. Lung aerosol deposition in suckling infants. Arch Dis Child 2012;97:497-501.

68. Amirav I, Luder AS, Halamish A, et al. Design of aerosol face masks for children using computerized 3D face analysis. J Aerosol Med Pulm Drug Deliv 2014;27:272-8.

69. Amirav I, Newhouse MT, Luder A, et al. Feasibility of aerosol drug delivery to sleeping infants: a prospective observational study. BMJ Open 2014;4:e004124.

70. Moody GB, Ari A. Quantifying continuous nebulization via high flow nasal cannula and large volume nebulizer in a pediatric model. Pediatr Pulmonol 2020;55:2596-602.

71. Amirav I, Borojeni AA, Halamish A, et al. Nasal versus oral aerosol delivery to the "lungs" in infants and toddlers. Pediatr Pulmonol 2015;50:276-83.

72. Perry SA, Kesser KC, Geller DE, et al. Influences of cannula size and flow rate on aerosol drug delivery through the Vapotherm humidified high-flow nasal cannula system. Pediatr Crit Care Med 2013;14:e250-6.

73. Sunbul FS, Fink JB, Harwood R, et al. Comparison of HFNC, bubble CPAP and SiPAP on aerosol delivery in neonates: An in-vitro study. Pediatr Pulmonol 2015;50:1099-106.

74. Bhashyam AR, Wolf MT, Marcinkowski AL, et al. Aerosol delivery through nasal cannulas: an in vitro study. J Aerosol Med Pulm Drug Deliv 2008;21:181-8.

75. Ari A, Harwood R, Sheard M, et al. In vitro comparison of heliox and oxygen in aerosol delivery using pediatric high flow nasal cannula. Pediatr Pulmonol 2011;46:795-801.

76. Li J, Gong L, Ari A, et al. Decrease the flow setting to improve trans-nasal pulmonary aerosol delivery via "high-flow nasal cannula" to infants and toddlers. Pediatr Pulmonol 2019;54:914-21.

77. Li J, Gong L, Fink JB. The Ratio of Nasal Cannula Gas Flow to Patient Inspiratory Flow on Trans-nasal Pulmonary Aerosol Delivery for Adults: An in Vitro Study. Pharmaceutics 2019;11:225.

78. Alalwan MA, Fink JB, Ari A. In vitro evaluation of aerosol drug delivery with and without high flow nasal cannula in children. Pediatr Pulmonol 2019;54:1968-73.

79. Reminiac F, Vecellio L, Bodet-Contentin L, et al. Nasal high-flow bronchodilator nebulization: a randomized cross-over study. Ann Intensive Care 2018;8:128.

80. Réminiac F, Vecellio L, Heuzé-Vourc'h N, et al. Aerosol Therapy in Adults Receiving High Flow Nasal Cannula Oxygen Therapy. J Aerosol Med Pulm Drug Deliv 2016;29:134-41. 
81. Reminiac F, Vecellio L, Loughlin RM, et al. Nasal high flow nebulization in infants and toddlers: An in vitro and in vivo scintigraphic study. Pediatr Pulmonol 2017;52:337-44.

82. Amirav I, Shakked T, Broday DM, et al. Numerical investigation of aerosol deposition at the eyes when using a hood inhaler for infants--a 3D simulation. J Aerosol Med Pulm Drug Deliv 2008;21:207-14.

83. Shakked T, Broday DM, Katoshevski D, et al. Administration of aerosolized drugs to infants by a hood, a three-dimensional numerical study. J Aerosol Med 2006; 19:533-42.

84. Kugelman A, Amirav I, Mor F, et al. Hood versus mask nebulization in infants with evolving bronchopulmonary dysplasia in the neonatal intensive care unit. J Perinatol 2006;26:31-6.

85. Amirav I, Balanov I, Gorenberg M, et al. Nebuliser hood compared to mask in wheezy infants: aerosol therapy without tears! Arch Dis Child 2003;88:719-23.

86. Amirav I, Oron A, Tal G, et al. Aerosol delivery in respiratory syncytial virus bronchiolitis: hood or face mask? J Pediatr 2005;147:627-31.

87. Kim J, Xi J, Si X, et al. Hood nebulization: effects of head direction and breathing mode on particle inhalability and deposition in a 7-month-old infant model. J Aerosol Med Pulm Drug Deliv 2014;27:209-18.

88. D'Vaz N, Okitika TA, Shackleton C, et al. Bronchodilator responsiveness in children with asthma is not influenced by spacer device selection. Pediatr Pulmonol 2019;54:531-6.

89. Wildhaber JH, Janssens HM, Pierart F, et al. Highpercentage lung delivery in children from detergenttreated spacers. Pediatr Pulmonol 2000;29:389-93.

90. Laube BL, Janssens HM, de Jongh FH, et al. What the pulmonary specialist should know about the new inhalation therapies. Eur Respir J 2011;37:1308-31.

91. Kaditis AG, Winnie G, Syrogiannopoulos GA. Antiinflammatory pharmacotherapy for wheezing in preschool children. Pediatr Pulmonol 2007;42:407-20.

92. Amirav I, Newhouse MT, Minocchieri S, et al. Factors that affect the efficacy of inhaled corticosteroids for infants and young children. J Allergy Clin Immunol 2010;125:1206-11.

93. Ammari WG, Chrystyn H. Optimizing the inhalation flow and technique through metered dose inhalers of asthmatic adults and children attending a community pharmacy. $\mathrm{J}$ Asthma 2013;50:505-13.

94. Harnett CM, Hunt EB, Bowen BR, et al. A study to assess inhaler technique and its potential impact on asthma control in patients attending an asthma clinic. J Asthma 2014;51:440-5.

95. Hagmolen of ten Have W, van de Berg NJ, Bindels PJ, et al. Assessment of inhalation technique in children in general practice: increased risk of incorrect performance with new device. J Asthma 2008;45:67-71.

96. Pedersen S, Dubus JC, Crompton GK. The ADMIT series--issues in inhalation therapy. 5) Inhaler selection in children with asthma. Prim Care Respir J 2010;19:209-16.

97. Inhaler Error Steering C, Price D, Bosnic-Anticevich $\mathrm{S}$, et al. Inhaler competence in asthma: common errors, barriers to use and recommended solutions. Respir Med 2013;107:37-46.

98. Hanania NA, Braman S, Adams SG, et al. The Role of Inhalation Delivery Devices in COPD: Perspectives of Patients and Health Care Providers. Chronic Obstr Pulm Dis 2018;5:111-23.

99. Cain WT, Cable G, Oppenheimer JJ. The ability of the community pharmacist to learn the proper actuation techniques of inhaler devices. J Allergy Clin Immunol 2001;108:918-20.

100.Hanania N, Wittman R, Kesten S, et al. Medical personnel's knowledge of and ability to use inhaling devices: metered-dose inhalers, spacing chambers, and breath-actuated dry powder inhalers. Chest 1994;105:111.

101.Jones JS, Holstege CP, Riekse R, et al. Metered-dose inhalers: do emergency health care providers know what to teach? Ann Emerg Med 1995;26:308-11.

102. Bosnic-Anticevich SZ, Sinha H, So S, et al. Metereddose inhaler technique: the effect of two educational interventions delivered in community pharmacy over time. J Asthma 2010;47:251-6.

103. Kamps AW, van Ewijk B, Roorda RJ, et al. Poor inhalation technique, even after inhalation instructions, in children with asthma. Pediatr Pulmonol 2000;29:39-42.

104. Gillette C, Rockich-Winston N, Kuhn JA, et al. Inhaler Technique in Children With Asthma: A Systematic Review. Acad Pediatr 2016;16:605-15.

105. Kamps AWA, Brand PLP, Roorda RJ. Determinants of correct inhalation technique in children attending a hospital-based asthma clinic. Acta Paediatr 2002;91:159-63.

106. Fink JB. Inhalers in asthma management: is demonstration the key to compliance? Respir Care 2005;50:598-600.

107. De Benedictis FM, Selvaggio D. Use of inhaler devices in pediatric asthma. Paediatr Drugs 2003;5:629-38.

108. Deerojanawong J, Promsaka na Sakolnakorn V, Prapphal $\mathrm{N}$, et al. Evaluation of metered-dose inhaler administration technique among asthmatic children and their caregivers 
in Thailand. Asian Pac J Allergy Immunol 2009;27:87-93.

109.Pedersen S, Hansen O, Fuglsang G. Influence of inspiratory flow rate upon the effect of a Turbuhaler. Arch Dis Child 1990;65:308.

110. Sleath B, Ayala GX, Gillette C, et al. Provider demonstration and assessment of child device technique during pediatric asthma visits. Pediatrics 2011;127:642-8.

111. Schultz A, Le Souëf TJ, Venter A, et al. Aerosol inhalation from spacers and valved holding chambers requires few tidal breaths for children. Pediatrics 2010;126:e1493-8.

112. Roller CM, Zhang G, Troedson RG, et al. Spacer inhalation technique and deposition of extrafine aerosol in asthmatic children. Eur Respir J 2007;29:299-306.

113. Wildhaber JH, Devadason SG, Eber E, et al. Effect of electrostatic charge, flow, delay and multiple actuations on the in vitro delivery of salbutamol from different small volume spacers for infants. Thorax 1996;51:985-8.

114. Wildhaber JH, Devadason SG, Hayden MJ, et al. Electrostatic charge on a plastic spacer device influences the delivery of salbutamol. Eur Respir J 1996;9:1943-6.

115.Piérart F, Wildhaber J, Vrancken I, et al. Washing spacers in household detergernt reduces electrostatic charge and greatly improves delivery. Eur Respir J 1999;13:673-8.

116. Dompeling E, Oudesluys-Murphy AM, Janssens HM, et al. Randomised controlled study of clinical efficacy of spacer therapy in asthma with regard to electrostatic charge. Arch Dis Child 2001;84:178-82.

117. Anhoj J, Bisgaard H, Lipworth BJ. Effect of electrostatic charge in plastic spacers on the lung delivery of HFAsalbutamol in children. Br J Clin Pharmacol 1999;47:333-6.

118. Bisgaard H, Anhoj J, Klug B, et al. A non-electrostatic spacer for aerosol delivery. Arch Dis Child 1995;73:226-30.

119.Janssens HM, Tiddens HA. Facemasks and aerosol delivery by metered dose inhaler-valved holding chamber in young children: a tight seal makes the difference. J Aerosol Med 2007;20 Suppl 1:S59-63; discussion S63-5.

120. Esposito-Festen J, Ates B, van Vliet F, et al. Aerosol delivery to young children by pMDI-spacer: is facemask design important? Pediatr Allergy Immunol 2005;16:348-53.

121.Esposito-Festen JE, Ates B, van Vliet FJ, et al. Effect of a facemask leak on aerosol delivery from a pMDI-spacer

Cite this article as: Ari A. A path to successful patient outcomes through aerosol drug delivery to children: a narrative review. Ann Transl Med 2021;9(7):593. doi: 10.21037/atm-201682 system. J Aerosol Med 2004;17:1-6.

122. Amirav I, Newhouse MT. Aerosol Therapy With Valved Holding Chambers in Young Children: Importance of the Facemask Seal. Pediatrics 2001;108:389.

123. Rubin BK. Bye-Bye, Blow-by. Respiratory Care 2007;52:981.

124. Restrepo RD, Dickson SK, Rau JL, et al. An investigation of nebulized bronchodilator delivery using a pediatric lung model of spontaneous breathing. Respiratory Care 2006;51:56-61.

125. Wildhaber JH, Dore ND, Wilson JM, et al. Inhalation therapy in asthma: nebulizer or pressurized metered-dose inhaler with holding chamber? In vivo comparison of lung deposition in children. J Pediatr 1999;135:28-33.

126. Tal A, Golan H, Aviram M. Deposition pattern of radiolabeled salbutamol inhaled from a metered-dose inhaler by means of a spacer with mask in young children with airway obstruction. J Pediatr 1996;128:479-84.

127. Murakami G, Igarashi T, Adachi Y, et al. Measurement of bronchial hyperreactivity in infants and preschool children using a new method. Ann Allergy 1990;64:383-7.

128. Janssens HM, Tiddens HAW. Aerosol therapy: The special needs of young children. Paediatr Respir Rev 2006;7:S83-5.

129. Esposito-Festen JE, Ijsselstjin H, Hop W, et al. Aerosol therapy by pMDI-spacer in sleeping young children: to do or not to do? Chest 2006;130:487-92.

130. Bokhour BG, Cohn ES, Cortés DE, et al. Patterns of concordance and non-concordance with clinician recommendations and parents' explanatory models in children with asthma. Patient Educ Couns 2008;70:376-85.

131. Weinstein AG. The potential of asthma adherence management to enhance asthma guidelines. Ann Allergy Asthma Immunol 2011;106:283-91.

132. Eakin MN, Rand CS. Improving patient adherence with asthma self-management practices: what works? Ann Allergy Asthma Immunol 2012;109:90-2.

133. Basheti IA, Armour CL, Bosnic-Anticevich SZ, et al. Evaluation of a novel educational strategy, including inhaler-based reminder labels, to improve asthma inhaler technique. Patient Educ Couns 2008;72:26-33. 